\title{
Effects of Melatonin-Aided Therapy on the Glutathione Antioxidant System Activity and Liver Protection
}

\author{
Serguey S. Popov, ${ }^{1}$ Konstantin K. Shulgin, ${ }^{2}$ Tatyana N. Popova, ${ }^{2}$ \\ Aleksander N. Pashkov, ${ }^{3}$ Aleksander A. Agarkov, ${ }^{2}$ and Miguel A. A. Pinheiro de \\ Carvalho $^{4,5}$ \\ ${ }^{1}$ Department of Endocrinology, Voronezh State Medical Academy, Voronezh, Russian Federation \\ ${ }^{2}$ Department of Medical Biochemistry and Microbiology, Voronezh State University, Voronezh, Russian Federation \\ ${ }^{3}$ Department of Biology and Ecology, Voronezh State Medical Academy, Voronezh, Russian Federation \\ ${ }^{4}$ ISOPlexis Genebank, University of Madeira, Funchal, Portugal; E-mail: quercus@uma.pt \\ ${ }^{5}$ ICAAM, University of Evora, Portugal
}

Received 30 December 2014; revised 6 March 2015; accepted 10 March 2015

\begin{abstract}
Acute hepatitis results from oxidative stress triggered by hepatotoxic drugs causing liver injury and the activation of caspases cascade. The glutathione antioxidant system protects against reactive oxygen species and mitigates development of these processes. The effectiveness of silymarin, a polyphenolic flavonoid, essenthiale, composed of phosphatidyl choline, and melaxen, a melatonincorrecting drug, as hepatoprotectors has been investigated. The variation of 6-sulfatoxymelatonin (aMT6s), resulting from the biotransformation of melatonin, and GSH has been measured. The activities of caspase1 and caspase-3, glutathione antioxidant system, and NADPH-generating enzymes were determined. The aMT6s decreases in patients with drug hepatitis and recovers with administration of mexalen. GSH increased in the presence of the studied hepatoprotectors. Pathologically activated caspase- 1 and caspase- 3 decreased their activities in the presence of hepatoprotectors with melaxen showing the highest effect. The positive effect of melatonin appears to be related to the suppression of decompensation of the glutathione antioxidant system functions, recovery of liver redox status, and the attenuation of inhibition of the NADPH supply. $\odot 2015 \mathrm{Wi}$ ley Periodicals, Inc. J. Biochem. Mol. Toxicol. 29:449-457, 2015; View this article online at wileyonlinelibrary.com. DOI $10.1002 /$ jbt.21705
\end{abstract}

KEYWORDS: Drug-induced hepatitis; Glutathione antioxidant system; 6-Sulfatoxymelatonin; Reduced gluthatione; Hepatoprotectors

Correspondence to: Miguel A. A. Pinheiro de Carvalho (C) 2015 Wiley Periodicals, Inc.

\section{INTRODUCTION}

Acute hepatitis often occurs as a result of the formation of reactive metabolites in the liver. Hepatotoxic drugs can injure the hepatocyte directly via production of free radical or through metabolite peroxidation of membrane lipids. Reactive oxygen species (ROS) have been implicated in the drug-induced injury. In tuberculosis, inflammatory mediators and oxidative stress may potentiate drugs hepatotoxicity. In these processes, the death ligands, Fas ligand, tumor necrosis factor $\alpha$ (TNF- $\alpha$ ), and their cognate receptors can induce liver injury by triggering hepatocyte apoptosis and necrosis [1], activating in the caspases cascade. Caspase- 1 and caspase- 3 are inflammatory and apoptotic enzymes, signaling ongoing cell damaging processes during hepatitis [2]. Apoptosis may be controlled by the redox status of the hepatocyte $[3,4]$, constituting a defense mechanism against acute hepatitis $[5,6]$.

The tissue redox status depends on complex enzymatic mechanisms, whereas the glutathione antioxidant system plays a central role. Glutathione in the reduced (GSH) or oxidized (GSSG) forms, glutathione peroxidase (GPx; EC 1.11.1.9), glutathione reductase (GRx; EC 1.6.4.2), and glutathione S-transferase (GST; EC 2.5.1.18) are involved in the glutathione antioxidant system [7-10]. The system requires supply of NADPH provided by glucose-6-phosphate dehydrogenase (G6PD; EC 1.1.1.49) or NADP-isocitrate dehydrogenase (NADP-IDH; EC 1.1.1.42) [11, 12].

GSH in its reduced form is thought to be the most important intracellular defense against ROS. Its free sulfhydryl group provides an antenna for attack by different oxidative species [7]. GPx uses GSH as 
substrate to neutralize hydrogen peroxide and lipid peroxides. Oxidized glutathione (GSSG) is further recycled to its reduced form by GRx using NADPH $[8,9]$. One of the major cellular suppliers of NADPH for the glutathione antioxidant system is the pentose phosphate pathway, where G6PD catalyzes transformation of glucose-6-phosphate into 6-phosphogluconolactone with production of NADPH [11]. The needs of the GPx/GRx system for NADPH enhances the disorders disruption of the tissue antioxidative defenses [13]. Alternatively NADPH can be generated by NADP-IDH, which promotes oxidizing decarboxylation of isocitrate into 2-oxoglutarate [12]. Additionally, GST is involved in the antioxidant protection and detoxification of harmful toxic compounds using GSH as a substrate [10], avoiding activation of the reactive oxidative cascade. Therefore, the tissue glutathione antioxidant system has clinical importance.

The glutathione antioxidant system can fail in the defense of liver from injury caused by antituberculosis drugs. In such instance, hepatoprotectors can assist in recovery of the antioxidative status and regenerate damaged tissue. Silymarin, a herbal drug, exhibits hepatoprotective properties due to antioxidant power of the polyphenolic flavonoids [14]. Essenthiale composed of phosphatidyl choline promotes regeneration of cell membranes and suppresses oxidative stress [15]. Melatonin secreted by several body tissues is involved in synchronization of the organism circadian and seasonal biorhythms and present at high concentrations in the mitochondria and cell nucleus, whereas can act as a free radical scavenger [16] effectively protecting membranes, nucleus, and mitochondrial DNA. The possible protective role of melatonin against pathological processes during drug-induced hepatitis is still unknown. Melaxen, a melatonin-regulating drug, could be used to understand its role in liver protection [17]. 6-Sulfatoxymelatonin (aMT6s), major metabolite of melatonin [18], was used to study the hormone metabolism under stress conditions [19].

This work aims to evaluate effectiveness of hepatoprotectors as potential activators of glutathione antioxidant system in the mitigation of inflammatory and apoptotic processes and protection of liver tissue against injuries caused by antituberculosis drugs.

\section{MATERIAL AND METHODS}

\section{Study Subject and Sample Groups}

A group of 131 individuals, adult man and women were included in the present study (Table 1). Sixtysix individuals with drug-induced hepatitis including 42 man $(64 \%)$ and 24 woman (36\%), age ranging from
18 to 56 years, were used as the experimental groups. All patients who suffered from lungs tuberculosis were treated at the Voronezh regional antitubercular clinics. Diagnoses of a drug-induced hepatitis were made using evaluation of the clinical symptoms, biochemical blood analysis, and an ultrasound exam of the liver. On average, the disease lasted $2.6 \pm 0.4$ month. The control group was composed of 65 generally healthy people, age ranging from 21 to 52 years, with normal parameters of the general and biochemical blood samples.

Drug-induced hepatitis patients were subdivided into two groups. The first group included 35 patients submitted for 10 days to a standard treatment with hepatoprotectors (silymarine and essenthiale). The second group of 31 individuals received the same standard therapy supplemented with one tablet per day of melaxen (Unifarm, New York, NY, USA) containing $3 \mathrm{mg}$ melatonin. The treatment was administered 30-40 $\mathrm{min}$ before bed time for 10 days.

\section{Blood and Urine Samples}

Blood serum and urine samples were collected from all individuals twice, at the beginning and end of the study, using standard sampling methods.

\section{Biochemical Parameters Analysis}

The BÜHLMANN 6-sulfatoxymelatonin ELISA kit (EK-M6S) was used for the direct and quantitative determination of aMT6s in human urine. The assay used a capture antibody principal based on polyclonal antibody specific for rabbit immunoglobulin coated onto the microtiter plates. The analysis requires $5 \mu \mathrm{L}$ of urine and has a range sensitivity of $0.8-40 \mathrm{ng} / \mathrm{mL}$. GSH concentration was determined through the reaction with 5,5-dithio-bis-(2-nitrobenzoic) acid [20]. Protein content in blood serum samples was determined according to Lowry [21], using a bovine serum albumin calibration curve.

\section{Measurement of Enzyme Activity}

Caspase- 1 and caspase- 3 activities in blood serum were determined using colorimetric assay kits for caspase- 1 and caspase-3 (Sigma-Aldrich Lda, Dorset, UK), respectively. The caspase activity was measured at the $405 \mathrm{~nm}$ (molar extinction coefficient $=$ $10.5)$ as the yield of $p$-nitroaniline resulting from the hydrolysis of the peptide substrates acetyl-tyr-ValAla-Asp- $p$-nitroanilide (Ac-YVAD-pnA) (for caspase-1) 
TABLE 1. Clinical Study Sample Major Features

\begin{tabular}{|c|c|c|c|}
\hline & Control & Group I & Group II \\
\hline Man & $42(64 \%)$ & $42(64 \%)$ & \\
\hline Ages range (years) & $21-52$ & $18-56$ & \\
\hline Mean disease duration (months) & - & $2.6 \pm 0.4$ & \\
\hline Groups' size & 65 & 35 & 31 \\
\hline
\end{tabular}

and acetyl-Asp-Glu-Val-Asp-p-nitroanilide (Ac-DeVDpnA) (for caspase-3). Caspases specific activity was expressed in picomoles of the product formed during $1 \mathrm{~min}$ per $1 \mathrm{mg}$ of the protein.

Activities of other enzymes in blood serum were measured spectrophotometrically at the $340 \mathrm{~nm}$ with a Hitachi U-1900 spectrophotometer (Richmond Scientific, Lancashire, UK). Enzyme activity was expressed in catalytic units per $1 \mathrm{~mL}$ of serum and the enzyme specific activity as the number of catalytic units per $1 \mathrm{mg}$ of protein. One unit of catalytic activity (U) was defined as the amount of the enzyme activity performing the conversion of $1 \mu \mathrm{mol}$ of substrate per minute at $25^{\circ} \mathrm{C}$. GRx activity was measured in a reagent mixture with $50 \mathrm{mM}$ potassium phosphate buffer ( $\mathrm{pH}$ 7.4), $1 \mathrm{mM}$ ethylenediaminetetraacetic acid (EDTA), $0.16 \mathrm{mMNADPH}$, and $0.8 \mathrm{mM}$ oxidized glutathione (GSSG). GPx activity was assayed in the reagent mixture with $50 \mathrm{mM}$ potassium phosphate buffer (pH 7.4), 1 mM EDTA, $0.12 \mathrm{mM}$ NADPM, $0.85 \mathrm{mM} \mathrm{GSH}, 0.37 \mathrm{mM} \mathrm{H}_{2} \mathrm{O}_{2}$, and $1 \mathrm{U} / \mathrm{mL}$ GR. GST activity was determined using 1-chloro 2,4dinitro benzene (CDNB) [22] in a reagent mixture containing $0.1 \mathrm{M}$ potassium phosphate buffer $(\mathrm{pH}$ 6.5), $10 \mathrm{mM}$ GSH, and $1 \mathrm{mM}$ CDNB. G6PD activity was measured in the reagent mixture with $0.05 \mathrm{mM}$ Tris$\mathrm{HCl}$ buffer (pH 7.8), $3.2 \mathrm{mM}$ glucose-6-phosphate, and $0.25 \mathrm{mM}$ NADP. NADP-IDH activity was assayed in $0.05 \mathrm{~mm}$ Tris- $\mathrm{HCl}$ buffer ( $\mathrm{pH} 7.8)$ with $1.5 \mathrm{mM}$ isocitrate and $0.25 \mathrm{mM}$ NADP.

All enzymatic reactions have started by the addition of $100 \mu \mathrm{L}$ of blood serum to the reagent mixtures.

\section{Statistical Analysis}

Standard statistical methods were applied to evaluate the obtained data including calculation of mean values, SEM, Student's $t$-criterion, and the nonparametric Wilcoxon test using STATISTICA 6.0 software (StatSoft, Tulsa, OK, USA). Differences between the sample parameters and enzyme activities were considered statistically significant at $p \leq 0.05$.

\section{Ethical Issues}

This study was approved by the Ethical Committee of the Voronezh State Medical Academy governed by the Ministry of Health of Russian Federation. All procedures were carried out in accordance with The Code of Ethics of the World Medical Association (Declaration of Helsinki of 1975) for experiments involving humans.

\section{Reagents}

Chemicals used in this study were of the highest analytical grade available. NADP, NADPH, and GSH were obtained from Sigma. D,L-Isocitrate (trisodium salt) and glucose-6-phosphate were from Sigma Chemical (London, UK), and Tris was supplied by Serva (Germany).

\section{RESULTS}

The major features of the subjects included in the present study are shown in Table 1 . The drug-induced hepatitis was diagnosed based on a battery of three clinical tests, e.g., clinical observations, biochemical blood analysis, and ultrasound examinations. The candidates suffering from other diseases that could significantly increase the oxidative stress and affect glutathione antioxidant system activity such as viral hepatitis, malignant tumors, acute myocardial infarction, or acute impairment of the cerebral blood stream were excluded from this study.

The activity of caspases in blood serum of all patients with drug-induced hepatitis significantly exceeded the normal values. The specific activity of 
A

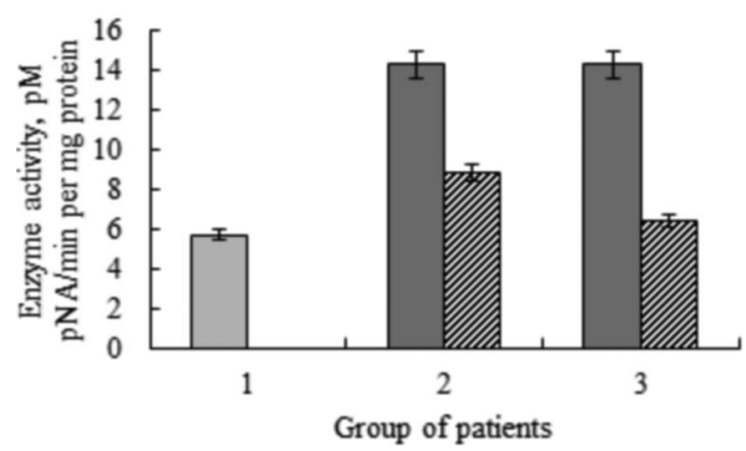

B

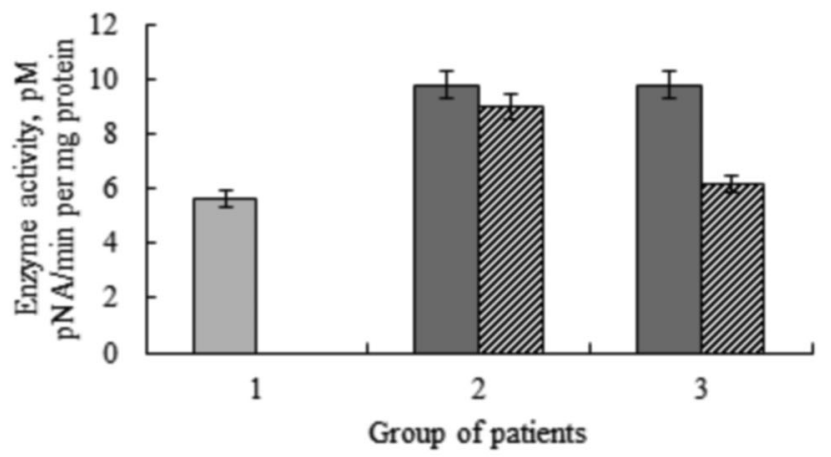

FIGURE 1. Variation of caspase-1 (A) and caspase-3 (B) specific catalytic activity in blood serum of control group (1), in patients with druginduced hepatitis, at the beginning (first column) and after 10 days (second column) of traditional therapy administration (2), and traditional therapy combined with melaxen (3): before (first column) and after (second column) therapy.

caspase- 1 and caspase- 3 in blood serum was 2.5 -fold $(p<0.05)$ and 1.7-fold $(p<0.05)$ higher, respectively, when compared to the corresponding activities of the control group. The standard therapy decreased the activity of caspase- 1 and caspase-3 by 1.6- and 1.1fold, respectively $(p<0.05)$. Additionally, melaxen administration inhibited caspases activity in a more profound way, which was, respectively, 2.2- and 1.6fold lower when compared to the values before the onset of therapy $p<0.05$ (Figure 1). These results indicate that inflammatory and apoptotic processes undergoing during the drug-induced hepatitis are accompanied by an increase in the caspases' activity that seem to be effectively inhibited by the hepatoprotectors particularly in the presence of melaxen.

Quantification of the aMT6s level in urine revealed a difference between the control group $\left(8.99 \mathrm{ng} \cdot \mathrm{mL}^{-1}\right)$ and the patients $\left(6.21 \mathrm{ng} \cdot \mathrm{mL}^{-1}\right)$ before the treatment (Figure 2). The standard and aided melaxen therapies allowed the recovery of aMT6s levels at $11.7 \%$ and to control $\left(9.12 \mathrm{ng} \cdot \mathrm{mL}^{-1}\right)$ levels, respectively. The results between control and experimental groups before the therapy and between the ontset and the final therapy with melaxen are statistically different, suggesting that melaxen enhances melatonin levels in the patient's blood and thus protects the liver.

Changes in the content of GSH blood serum in the control and experimental groups before and after 10 days of therapy indicate that consumption of reduced glutathione increases in patients with druginduced hepatitis (Figure 2). The GSH content was two fold lower compared to the control group. Lower content of GSH could be associated with a significantly increased demand for this metabolite during the intensification of free radical oxidation. The treatment with the hepatoprotectors allows a recovery of $56.8 \%$ of glutathione redox level in the standard therapy and return to the levels of control group in the patients under the therapy aided by melaxen. This increase correlates with changes in aMT6s and is clearly connected with the protective effect of melatonin and its positive action on the tissue glutathione redox status.

The fluctuations in the catalytic and specific activities of glutathione antioxidant system enzymes (GPx, GRx, and GST) in the control and experimental groups before and after 10 days therapy have been analyzed. An enhancement of GPx and GRx activities and a decrease in GST were observed in patients with druginduced hepatitis when compared to the control group. GPx and GRx activities in the patients groups before the therapy were 1.3- and 2.2-fold $(p<0.05)$ higher than the control group. The enzymes specific activity exhibited the same trend with the increase in 1.1- and 1.4-fold $(p<0.05)$. This initial stimulation of the GPx/GRx system could be due to its induction to counteract the effect of uncontrolled ROS production and oxidative stress during the pathology development. Oxidative stress simultaneously enhanced the apoptotic processes, which was reflected by the increase in the caspases activity. Administration of the hepatoprotectors through standard therapy promoted the activation of GPx and GRx 1.2-fold ( $p<0.05)$ and 1.1-fold, respectively, when compared to the onset of the treatment. This enhancement was accompanied by gains in the GPx and GRx specific activities, which rose $18.5 \%(p<0.05)$ and 5.3\%, respectively. The GPx and GRx activities also exceeded normal values in the patients' blood of the second group. However its variation range is larger, when the enzymes activity before the onset and the end of therapy was compared (Figure 3). Thus, therapy aided by melaxen resulted in a stronger GPx and GRx activation, with an increase in the catalytic activity by 2.1 - and 1.8-fold and 

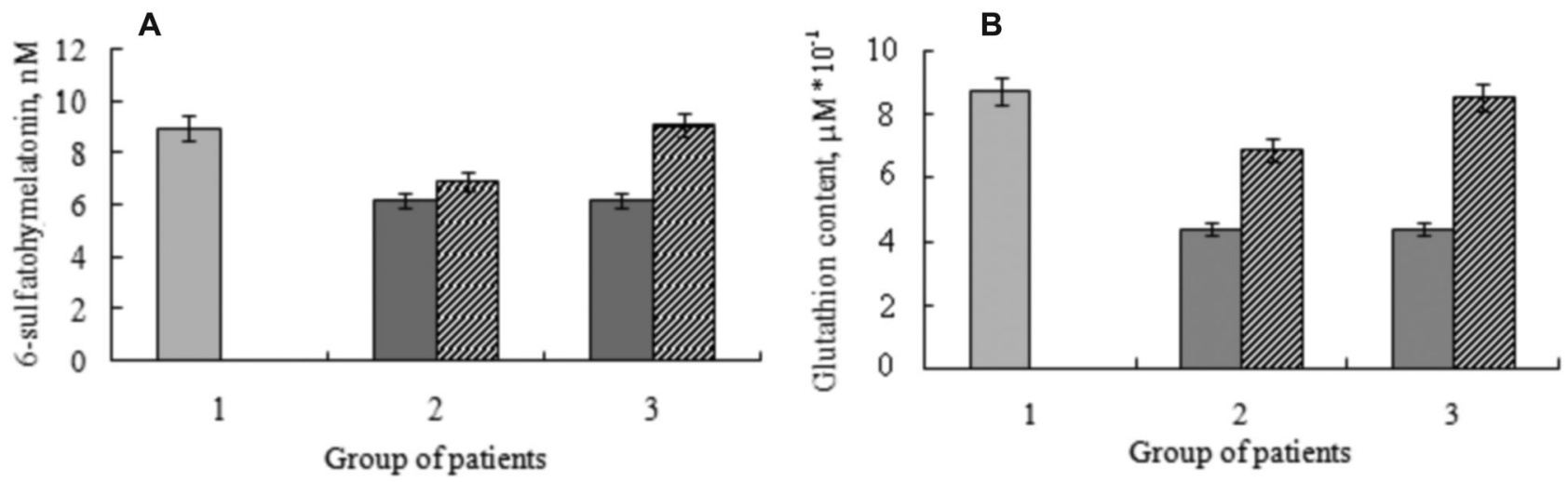

FIGURE 2. Variation of 6-sulfatoxymelatonin (A) and glutathione (B) content in blood serum of control group (1), in patients with drug-induced hepatitis, at the beginning (first column) and after 10 days (second column) of traditional therapy administration (2), and traditional therapy combined with melaxen (3): before (first column) and after (second column) therapy.
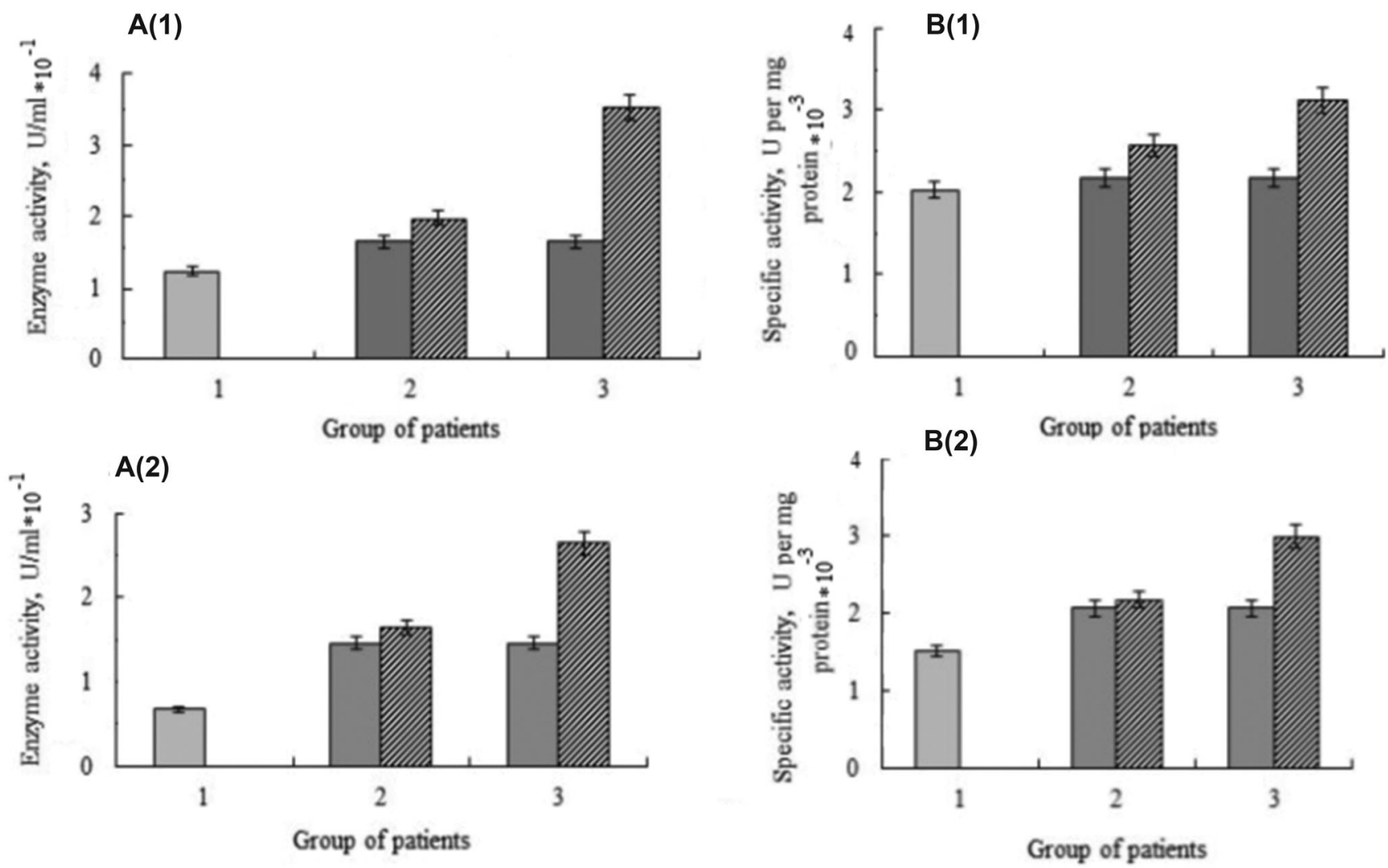

FIGURE 3. Variation of glutathione peroxidase (GPx; EC 1.11.1.9) (1) and glutathione reductase (GRx; EC 1.6.4.2) (2) catalytic activity expressed in $\mathrm{U} / \mathrm{mL}$ (A) and specific catalytic activity expressed in $\mathrm{U} / \mathrm{mg}$ protein (B) in blood serum of control group (1), in patients with drug-induced hepatitis, at the beginning (first column) and after 10 days (second column) of traditional therapy administration (2), and traditional therapy combined with melaxen (3): before (first column) and after (second column) therapy.

specific catalytic activity by $1.4-$ and 1.5 -fold, respectively $(p<0.05)$. The enhancement of GPx and GRx specific activities could indicate a possible induction of enzymatic expression in the presence of melaxen.

The decrease in GST activity in blood serum (Figure 4$)$ was 1.6-fold $(p<0.05)$ lower, while its specific activity was 1.7 -fold lower in comparison with the control group. The decrease in GST activity may be associated with competition for GSH when its turnover through the GPx/GRx system increases to prevent oxidative damage caused by ROS to the cellular and tissue structures. Standard therapy increased GST activity and specific activity by 1.5 -fold $(p<0.05)$ and 1.4-fold, respectively, in comparison with the onset of 
A

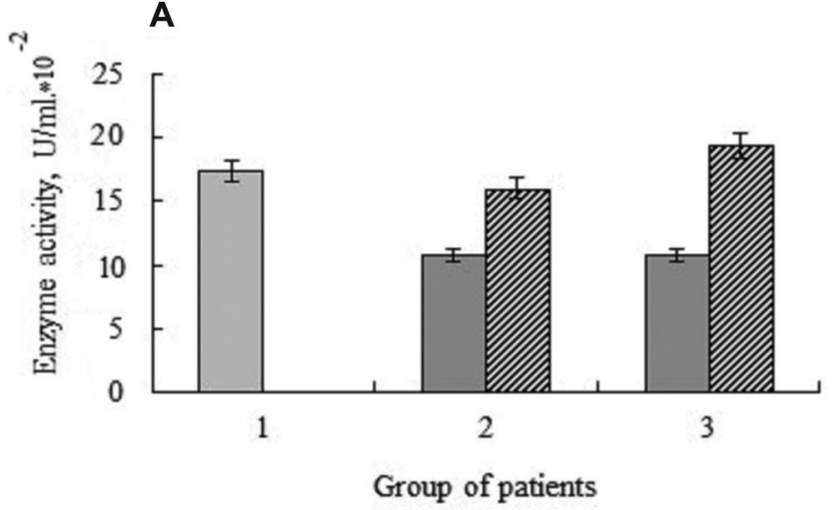

B

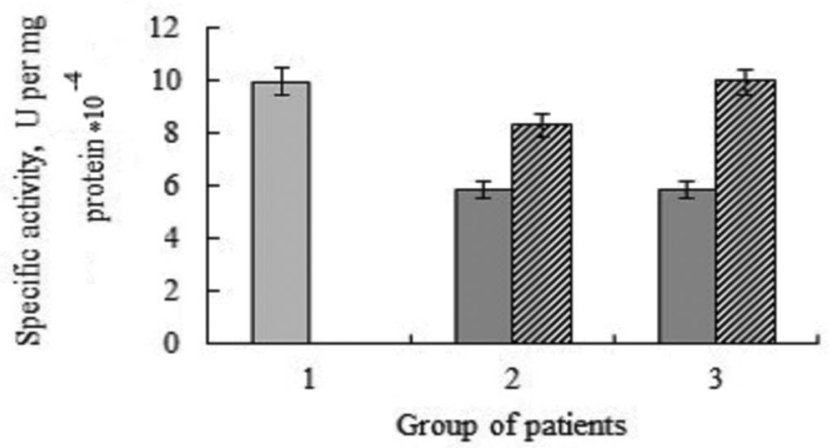

FIGURE 4. Variation of glutathione transferase (GST; EC 2.5.1.18) catalytic activity expressed in U/mL (A) and specific catalytic activity expressed in $\mathrm{U} / \mathrm{mg}$ protein (B) in blood serum of control group (1), in patients with drug-induced hepatitis, at the beginning (first column) and after 10 days (second column) of traditional therapy administration (2), and traditional therapy combined with melaxen (3): before (first column) and after (second column) therapy.

the therapy. This increase could be perhaps connected with the enhancement of the GSH cellular pool as a result of the hepatoprotectors action, which allows GST to participate in the protective mechanism directly neutralizing drug toxins. Similarly, the GST activity and specific activity in the patients of the second group has also increased by 1.8 -fold $(p<0.05)$ and 1.7 -fold $(p<0.05)$, respectively, after the therapy aided by melaxen. These data are consistent with the availability of high cellular GSH concentration (Figure 2) promoted by the GRx (Figure 3), which is the primary substrate of GST acting as an acceptor of the antituberculosis drugs. Perhaps a certain predetermined level of GSH is needed to raise GST activity, which in turn could occur through the enzyme induction under oxidative stress.

The activity of glutathione antioxidant system and regeneration of GSH under oxidative stress require a constant supply of NADPH as reduction power, which could be supported by the work of G6PD or NADPIDH. However, a decrease in the G6PD activity and specific activity of 1.5 -fold $(p<0.05)$ and 1.4 -fold, respectively, was observed in blood samples of the patients when compared to the control group (Figure 5). G6PD is a main supplier of NADPH for GSH regeneration by GRx and the decrease in its activity is consistent with GSH lowest levels and decrease in GST activity. At the same time, the catalytic activity and the specific activity of NADP-IDH in the blood serum of patients groups before the therapy was 1.3- and 1.1-fold lower than in the control group. NADP-IDH is an alternative supplier of NADPH for GSH regeneration by GRx and its inhibition is consistent with the observed decrease in GSH levels and GST activity during drug-induced hepatitis.

After the standard therapy, the activity of G6PD and NADP-IDH increased by $25.3 \%$ and $10.6 \%$, re- spectively. Similarly, G6PD and NADP-IDH specific activities raised by 1.3- and 1.1-fold, respectively (Figure 5). This difference was evidently related to the positive effect of the hepatoprotectors on the hepatocytes metabolism and could be coupled with activation of glutathione antioxidant system and GTS (conjugation function) observed after the treatment with carsil and/or essenthiale. The therapy aided by melaxen showed to be even more effective and resulted in the 1.7- and 1.2-fold increase in G6PD and NADPIDH activities. At the same time, G6PD and NADPIDH specific activities increased by 1.5 -fold $(p<0.05)$ and 1.2-fold. Activation of the NADPH-generating enzymes was higher when the standard treatment was combined with melaxen. This activation resulted in a significant increase in all enzymatic activities (GRx, GPx, and GST) of the glutathione antioxidant system (Figures 3 and 4).

Comprehensive analysis of these data indicates that melatonin can play a role of an adaptogene capable to promote a regulatory action on free radical homeostasis and apoptosis processes, positively influencing the ROS scavenging potential of tissue through the activation of glutathione antioxidant system supported by the NADP-supplying enzymes during oxidative stress caused by drugs during hepatitis.

\section{DISCUSSION}

In the liver, cytochrome $\mathrm{P} 450$ is the defense against cells damage performing drugs bioinactivation. Neutralization of xenobiotics additionally leads to the ROS production, inducing the oxidative stress. Oxidative conditions can stimulate Fas ligand synthesis enhancing hepatocytes susceptibility to apoptosis [23]. The Fas 

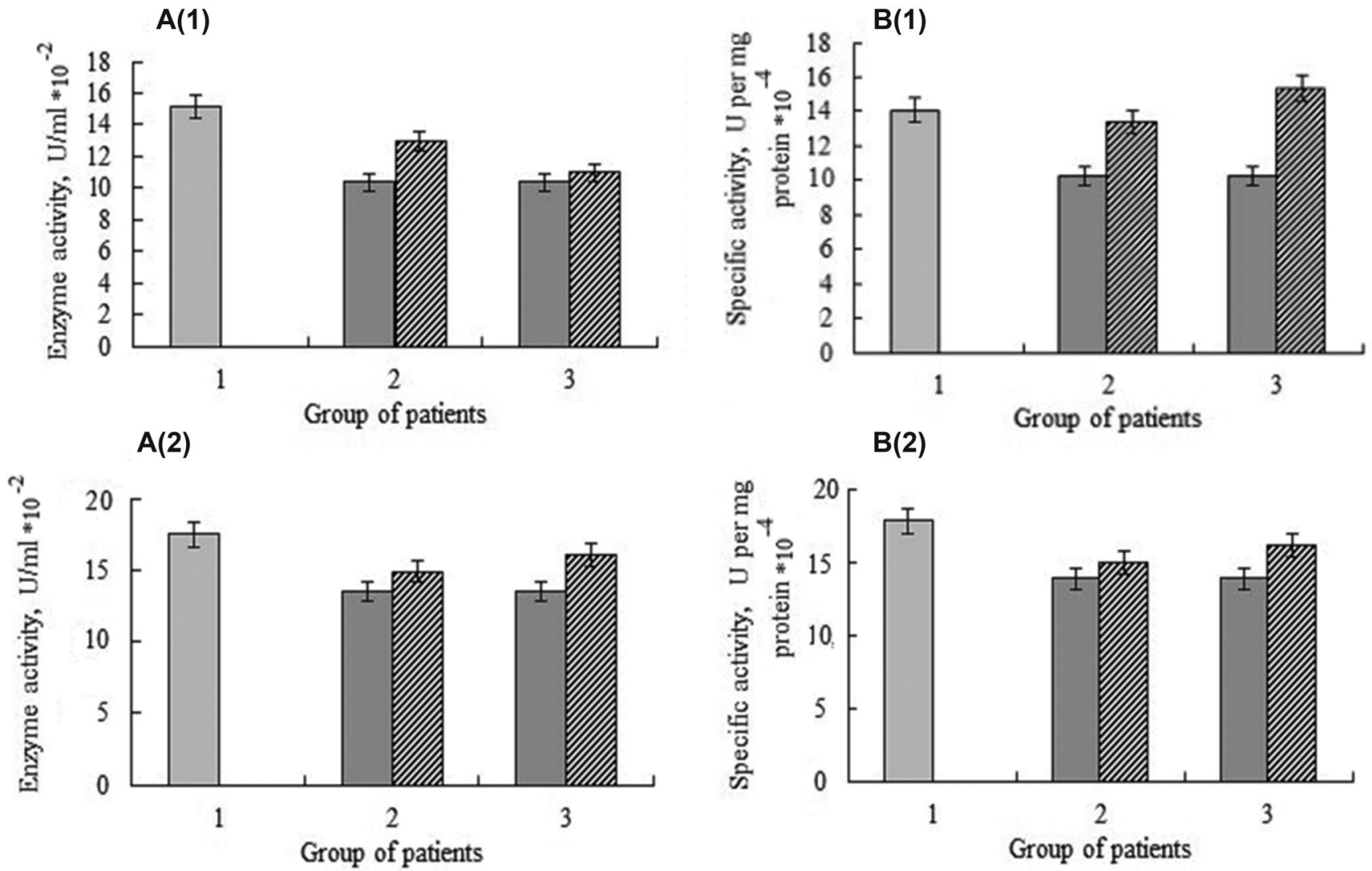

FIGURE 5. Variation of glucose-6-phosphate dehydrogenase (G6PD; EC 1.1.1.49) (1) and NADP-dependent isocitrate dehydrogenase (NADPIDH; EC 1.1.1.42) (2) catalytic activity expressed in U/mL (A) and specific catalytic activity expressed in U/mg protein (B) in blood serum of control group (1), in patients with drug-induced hepatitis, at the beginning (first column) and after 10 days (second column) of traditional therapy administration (2), and traditional therapy combined with melaxen (3): before (first column) and after (second column) therapy.

$\mathrm{L}$ is exceeded in acute liver failure as a result of its expression [24] and is suggested to activate the caspases. The enhancement of caspases activity is associated with the oxidative stress and Fas-mediated apoptotic processes. The increase in the caspases activity during Fas-induced apoptosis [24] results from sequential activation of caspase-1- and caspase-3-like proteases [25] and can be suppressed by enzyme inhibitors [24]. The decrease in caspases activity was also associated with hepatoprotectors, where melaxen demonstrated the stronger effect. Melatonin positively inhibits the apoptotic processes by enhancing the expression of antiapoptotic Bcl-2 genes [26, 27]. Melaxen intake corrects melatonin levels, attenuating free radical oxidation and inhibiting inflammatory and apoptotic processes.

The role of melatonin in ROS neutralization can be estimated based on aMT6s changes [19, 28], in which reduction is associated with melatonin use as a ROS scavenger, reacting with peroxyl radicals [29], singlet oxygen species [30], and hydrogen peroxide with the formation of 3-hydroxymelatonin [31]. Melatonin metabolites including aMT6s can themselves detoxify radicals $[32,33]$. These events are named "antioxidant cascade of melatonin" [33,34]. The aMT6s variation in the presence of hepatoprotectors shows an increase in liver protection by this cascade.

The GSH variation is consistent with its direct use in ROS scavenging [35] or indirectly in enzymatic processes, providing tissues antioxidant defense [7]. Carsil and essenthiale promote the GSH increase, decreasing ROS activity. Higher GSH in the presence of melaxen can be explained by melatonin synergistic action on ROS scavenging and glutathione antioxidant system activity. Enhanced glutathione antioxidant system oxidation and reduction functions are a response to ROS activity. GPx is induced by oxidative stress [36], increasing the needs for GSH not sufficiently compensated by the GRx. The positive effect of hepatoprotectors results in an overall increase in GAS, including conjugation (GST) function. Melatonin promotes the NADPH-dependent GSSG reduction by GRx [37], surpassing the needs for GSH [38], which is consistent with higher GRx activity in the presence of melaxen. The increase in GSH and aMT6s support these observations 
and indicate that melatonin activity can be connected with the expression of antioxidant enzymes [16]. The decrease in GST activity may be associated with competition of the GPx/GRx system for GSH. GST is a key enzyme in drugs detoxification through conjugation [39], removing them from the blood [10] and avoiding the beginning of stress cascade.

G6PD activity decrease is consistent with gluconeogenesis hampering and glycolysis enhancement in the injured liver [40], with the suppression of the anaplerotic branchpoint of pentose phosphate pathway. Suppression of the oxidative metabolism during liver intoxication is connected with metabolic disorders in hypoxic conditions [40]. Glutathione antioxidant system mobilization can be limited also by the NADP-IDH inhibition affecting the NADPH supply [41] and GST [39]. The inhibition of NADPH supplying enzymes might be the main causes of GSH decrease. The distinguished effects of the hepatoprotectors with more effective action of melaxen on the glutathione antioxidant system activity are consistent with this system induction after exposure to melatonin [42].

\section{CONCLUSIONS}

Our study demonstrated that drug-induced hepatitis is accompanied by a decrease in aMT6s and GSH levels, enhancement of caspase- 1 and caspase- 3 activity, and disturbances of the glutathione antioxidant system activity. The reduction of aMT6s and GSH at pathology is explained by the dilapidation of melatonin and GSH in ROS neutralization. The increase in caspase- 1 and caspase- 3 activities is an indicator of undergoing inflammatory and apoptotic processes mediated by the Fas receptor. The decrease in GSH content and the GST activity reflects the disturbance of glutathione antioxidant system functioning under oxidative stress that is not compensated by the increase in GRx and GPx activity. Therapy with the hepatoprotectors aided with melaxen seems to be effective to compensate the disorders in the function of enzyme and nonenzyme components of the glutathione antioxidant system. It can be concluded that correction of tissue oxidant-antioxidant status is an important part of the effective therapy against drug-induced hepatitis.

\section{ACKNOWLEDGMENT}

This work was supported by grant of the President of the Russian Federation for young scientists MK3133.2011.7. Authors thank to President of Voronezh State Medical Academy named after N. N. Burdenko
(Russia), Prof. Igor E. Esaulenko, for advice and suggestions.

\section{REFERENCES}

1. Montgomery Bissell D, Gores GJ, Laskin DL, Hoofnagle JH. Drug-induced liver injury: mechanisms and test systems. Hepatology 2001;33(4):1009-1013.

2. McIlwain DR, Berger Th, Mak TK. Caspase functions in cell death and disease. Cold Spring Harb Perspect Biol 2013;5(a008656):1-29.

3. Hentze H, Gantner F, Kolb SA, Wendel A. Depletion of hepatic glutathione prevents death receptor-dependent apoptotic and necrotic liver injury in mice. Am J Pathol 2000;156:2045-2056.

4. Latta M, Kunstle G, Leist M, Wendel A. Metabolic depletion of ATP by fructose inversely controls CD 95- and tumor necrosis factor receptor 1-mediated hepatic apoptosis. J Exp Med 2000;191:1975-1985.

5. Lukaszewicz-Hussain A, Moniuszko-Jakoniuk J. Liver catalase, glutathione peroxidase and reductase activity, reduced glutathione and hydrogen peroxide levels in acute intoxication with chlorfenvinphos, an organophosphate insecticide. Polish J Environ Stud 2004;13(3):303309.

6. Schaberg T, Rebhan K, Lode H. Risk factors for sideeffects of isoniazid, rifampin and pyrazinamide in patients hospitalized for pulmonary tuberculosis. Eur Respir J 1996;9:2026-2030.

7. Szalai G, Kellos T, Galiba G, Kocsy G. Glutathione as an antioxidant and regulatory molecule in plants under abiotic stress conditions. J Plant Growth Regul 2009;28:6680.

8. Eshdat Y, Holland D, Faltin Z, Benhayyim G. Plant glutathione peroxidases. Physiol Plant 1997;100:234240.

9. Ceballos-Picot I, Witko-Sarsat V, Merad-Boudia M, Nguyen AT, Thévenin M, Jaudon MCh, Zingraff J, Verger Ch, Jungers P, Descamps-Latscha B. Glutathione antioxidant system as a marker of oxidative stress in chronic renal failure. Free Radic Biol Med 1996;21(6):845853.

10. Smith GJ, Ohl VS, Ligandin LG. The glutathione Stransferases, and chemically induced hepato carcinogenesis. A review. Cancer Res 1977;37:8-14.

11. Ramnanan ChJ, Storey KB. Glucose-6-phosphate dehydrogenase regulation during hypometabolism. Biochem Biophys Res Commun 2006;339:7-16.

12. Medvedeva LV, Popova TN, Artiukov VG, Matasova LV, Pinheiro de Carvalho MAA. Intensity of free radical processes and regulation of cytoplasmic NADPisocitrate dehydrogenase in rat cardiomyocytes under normal and ischemic conditions. Biochemistry (Moscow) 2002;67(6):696-705.

13. Luzzato L, Metha A, Vulliamy T. Glucose 6-phosphate dehydrogenase deficiency. In: Scriver CR, Beaudet AL, Sly WS, editors. The metabolic and molecular bases of inherited disease, 8th edition. Columbus, OH: McGrawHill; 2001. pp 4517-4553.

14. Pradhan SC, Girish C. Hepatoprotective herbal drug, silymarin from experimental pharmacology to clinical medicine. Indian J Med Res 2006;124:491-504.

15. Aleynik AI, Leo MA, Aleynik MK, Lieber CS. Polyenylphosphatidylcholine protects against alcohol 
but not iron-induced oxidative stress in the liver. Alcohol Clin Exp Res 2000;24:196-206.

16. Reiter RJ, Tan D, Mayo JC, Sainz RM, Leon J, Czarnocki Z. Melatonin as an antioxidant: biochemical mechanisms and pathophysiological implications in humans. Acta Biochim Pol 2003;50(4):1129-1146.

17. Oshima T, Pavlick KP, Laroux FS, Verma SK, Jordan P, Grisham MB, Williams L, Alexander JS. Regulation and distribution of MAdCAM-1 in endothelial cells in vitro. Am J Physiol Cell Physiol 2001;281:C1096-C1105.

18. Bespyatykh AY, Brodsky VYa, Burlakova OV, Golichenkov VA, Voznesenskaya LA, Kolesnikov DB, Molchanov AY, Rapoport SI. Melatonin: theory and practice. Moscow, Russia: Medical practice; 2009.

19. Arendt J. Melatonin and the mammalian pineal gland. London, UK: Chapman \& Hall; 1995.

20. Arutyunyan AV, Dubinin EE, Zybina NN. Methods of estimation of free radical oxidation and antioxidant system of an organism. St. Petersburg, Russia: IKF Foliant; 2000.

21. Lowry OH, Rosebrough NJ, Farr AL, Randall RJ. Protein measurement with the Folin-phenol reagent. J Biol Chem 1951;193:265-275.

22. Warholm M, Guthenberg C, von Bahr Ch, Mannervik B. Glutathione transferases from human liver. In: Melster A, editor. Methods of enzymology. New York: Academic Press; 1985. Vol 113, pp 500-501.

23. Soderman T, Bronk SF, Roberts PJ, Miyoshi H, Gores GJ. Bile salts mediate hepatocyte apoptosis by increasing cell surface trafficking of Fas. Am J Physiol Gastrointest Liver Physiol 2000;278:992-999.

24. Rutherford AE, Hynan LS, Borges CB, Forcione DG, Blackard JT, Lin W, Gorman AR, Obaid SS, Reuben A, Harrison E, Reddy KR, Le WM, Chung RT, and for the ALF Study Group. Serum apoptosis markers in acute liver failure: a pilot study. Clin Gastroenterol Hepatol 2007;5:1477-1483.

25. Ogasawara J, Watanabe-Fukunaga R, Adachi M, Matsuzawa A, Kasugai T, Kitamura Y, Iton N, Suda T, Nagata $\mathrm{S}$. Lethal effect of the anti-Fas antibody in mice. Nature 1993;364(6440):806-809.

26. Guha M, Maity P, Choubey V, Mitra K, Reiter RJ, Bandyopadhyay U. Melatonin inhibits free radical-mediated mitochondrial-dependent hepatocyte apoptosis and liver damage induced during malarial infection. J Pineal Res 2007;43:72-81.

27. Baydas G, Koz ST, Tuzcu M, Etem E, Nedzvetsky VS. Melatonin inhibits oxidative stress and apoptosis in fetal brains of hyperhomocysteinemic rat dams. J Pineal Res 2007;43:225-231.

28. Mathes AM. Hepatoprotective actions of melatonin: possible mediation by melatonin receptors. World J Gastroenterol 2010;16(48):6087-6097.

29. Pieri C, Marra M, Moroni F, Recchioni R, Marcheselli F. Melatonin: a peroxyl radical scavenger more effective than vitamin. E Life Sci 1994;55:PL271-PL276.
30. Cagnoli CM, Atabay C, Kharlamova E, Manev H. Melatonin protects neurons from singlet oxygen-induced apoptosis. J Pineal Res 1995;18:222-226.

31. Tan DX, Manchester LC, Reiter RJ, Plummer BF, Hardies LJ, Weintraub ST, Vijayalaxmi Shepherd AM. A novel melatonin metabolite, cyclic 3 -hydroxymelatonin: a biomarker of in vivo hydroxyl radical generation. Biochem Biophys Res Commun 1998;253:614-620.

32. Guenther AL, Schmidt SI, Laatsch H, Fotso S, Ness $\mathrm{H}$, Ressmeyer AR, Poeggeler B, Hardeland R. Reactions of the melatonin metabolite AMK (N1-acetyl5-methoxykynuramine) with reactive nitrogen species: formation of novel compounds, 3-acetamidomethyl-6methoxycinnolinone and 3-nitro-AMK. J Pineal Res 2005;39:251-260.

33. Tan DX, Manchester LC, Terron MP, Flores LJ, Reiter RJ. One molecule, many derivatives: a never-ending interaction of melatonin with reactive oxygen and nitrogen species? J Pineal Res 2007;42:28-42.

34. Reiter RJ, Tan DX, Manchester LC, Pilar Terron M, Flores LJ, Koppisepi S. Medical implications of melatonin: receptor-mediated and receptor-independent actions. Adv Med Sci 2007;52:11-28.

35. Smirnova GV, Oktyabrsky ON. Glutathione in bacteria. Biochemistry 2005;70(11):1199-1211.

36. Chandra R, Aneja R, Rewal C, Konduri R, Dass K, Aragwal S. An opium alkaloid-papaverine ameliorates ethanol induced hepatotoxicity: diminution of oxidative stress. Indian J Clin Biochem 2000;15(2):155160.

37. Baeza I, Fernandez-Tresguerres J, Ariznavarreta C, De la Fuente M. Effects of growth hormone, melatonin, oestrogens and phytoestrogens on the oxidized glutathione (GSSG)/reduced glutathione (GSH) ratio and lipid peroxidation in aged ovariectomized rats. Biogerontology 2010;11:687-701.

38. Agapito MT, Redondo I, Plaza R, Lopez-Burillo S, Recio JM, Pablos MI. Relationships between melatonin, glutathione peroxidase, glutathione reductase, and catalase. Endogenous rhythms on cerebral cortex in Gallus domesticus. Adv Exp Med Biol 1999;460:377-381.

39. Eaton DL, Bammler TK. Concise review of the glutathione S-transferase and their significance to toxicology. Toxicol Sci 1999;49:156-164.

40. Berezov TT. Biological chemistry. Moscow, Russia: Medicine; 2008.

41. Popova N, Pashkov NA, Semenihina AV, Popov SS, Rakhmanova TI. Free radical processes in the biological systems. St. Oskol, Russia: IPK Kirillica; 2008.

42. Iskusnykh IY, Popova TN, Agarkov AA, Pinheiro de Carvalho MAA, Rjevskiy SG. Expression of glutathione peroxidase and glutathione reductase and level of free radical processes under toxic hepatitis in rats. J Toxicol 2013; ID 870628:1-9. http:/ /dx.doi.org/10.1155/2013/870628. 